\title{
Drivers and Barriers for the development of Smart Sustainable Cities
}

\author{
A Systematic Literature Review \\ Luiza Schuch De Azambuja \\ Ragnar Nurkse Department of Innovation and Governance, Tallinn University of Technology, \\ FinEst Centre for Smart Cities, Tallinn University of Technology \\ Luiza.Schuch@taltech.ee
}

\begin{abstract}
The term Smart Sustainable City (SSC) has been gaining popularity due to the growth of initiatives to address urban problems towards sustainable development. SSC can be considered as a combination of sustainable city and smart city, and some variance between the concepts may be expected. As this is a modern term, the literature falls short of studies presenting factors that hinder and/or facilitate the complex phenomenon of SSC development. Therefore, this paper aims to analyse scientific studies to identify aspects that influence the progress of smart sustainable cities. The methodological approach undertaken was a systematic literature review that included 169 papers. The results offer a comprehensive list of 57 drivers and 63 barriers, classified according to five main dimensions of a smart sustainable city, which are the three sustainability pillars (society, environment, and economy), combined to governance, and urban infrastructure. The findings revealed 'governance' as the most significant domain for SSC development, and multistakeholder engagement as one of the main challenges. This study shows that SSC is not a research field itself, but an interdisciplinary concept, contributing to academics, government, and policymakers for eradicating potential interferences in the development of smart and sustainable cities.
\end{abstract}

\section{CCS CONCEPTS}

- Applied Computing; • Computers in other domains; • Computing in government $\rightarrow$ E-government;

\section{KEYWORDS}

sustainable city, smart city, challenges, enablers

\section{ACM Reference Format:}

Luiza Schuch De Azambuja. 2021. Drivers and Barriers for the development of Smart Sustainable Cities: A Systematic Literature Review. In 14th International Conference on Theory and Practice of Electronic Governance (ICEGOV 2021), October 06-08, 2021, Athens, Greece. ACM, New York, NY, USA, 7 pages. https://doi.org/10.1145/3494193.3494250

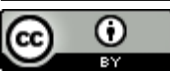

This work is licensed under a Creative Commons Attribution International 4.0 License.

ICEGOV 2021, October 06-08, 2021, Athens, Greece

(C) 2021 Copyright held by the owner/author(s).

ACM ISBN 978-1-4503-9011-8/21/10.

https://doi.org/10.1145/3494193.3494250
}

\section{INTRODUCTION}

The proliferation of smart initiatives brought new terms such as "smart city" and "sustainable city"; the first is related to the use of technology to improve urban services, whereas the second attempts for sustainable development [1]. Some academics have defended the adoption of the term "Smart Sustainable City (SSC)" [2-5], which can be understood as a combination of "smart city" and "sustainable city" [6]. Similarly, Höjer and Wangel [7] suggested that SSC should be seen as an aggregate concept that connects three parts: smart, sustainable and cities, in a way that cities could be sustainable without the use of technologies, or cities could use Information Communication Technologies (ICT) without contributing to sustainable development, but only when the three aspects are combined that we have a SSC. According to them, "A Smart Sustainable City is a city that meets the needs of its present inhabitants, without compromising the ability for other people or future generations to meet their needs, and thus, does not exceed local or planetary environmental limitations, and where this is supported by ICT" [7] (p. 10). A key aspect is that the use of technology in SSC should be as means to achieve better quality of life and long-term impacts.

Research on smart sustainable cities can be considered in its "initial stage" [8,9] and full of unexplored opportunities [3]. The development of SSCs is a complex phenomenon [10-12] that requires a holistic analysis; however, the majority of previous studies in this domain are focused on the technology side [13]. Furthermore, little effort has been made to investigate drivers, enablers, challenges and barriers for SSC development [6]. Few examples of related previous studies are focused on one region, for instance the identification of enablers affecting SSC development in the Indian context [14], SSC challenges faced in the Arab region [15], and the recent study of Khan et al. [16], which identified critical challenges faced by private and government organizations in Pakistan. Furthermore, there are available studies focused on smart cities drivers and barriers (not smart sustainable cities), as is the work of Guedes et al. [9], which identified potential smart city drivers, and $[17,18]$, which identified barriers for the implementation of smart city initiatives in India. Nevertheless, remains a need for an extensive and holistic review to outline both enablers and challenges influencing smart sustainable city development.

Considering the lack of studies outlining a synthesis of aspects that influence the progress of smart sustainable cities, the central question that guides this study is: "What are the main enablers and challenges for the development of Smart Sustainable Cities?". The methodological approach includes a systematic literature review. The enablers and challenges identified in the literature are classified 
according to the SSC conceptual model developed by Azambuja, Viale Pereira and Krimmer [6], which represents a smart sustainable city as an interplay of five main domains: the three pillars of sustainability (social, economic and environmental), urban infrastructure and governance.

The remainder of this paper has the following structure: The next section details the methodology implemented in this study; the third section presents the results of this study. The fourth section discusses the research findings and the last section concludes the discussion and explains the limitations of this study.

\section{METHODOLOGY}

This section explains the methodology of the literature review performed to identify factors that enable or hinder the development of smart sustainable cities (section 2.2) and briefly introduces the SSC conceptual framework (section 2.1) applied to classify the literature.

\subsection{Conceptual Framework}

This study considers a smart sustainable city a combination of "sustainable city" and "smart city". The term first term can be understood as a new attitude that balance its goals with the principles of sustainable development $[1,19]$, it is about people, natural system, learning, social changes and balanced conditions on a long-time horizon [19]. On the other hand, the term smart city is usually related to the use of technology and changes in services based on innovative approaches [19]. Thus, the addition of the word "sustainable" to the term smart city brings the idea that the benefits of smart sustainable city' initiatives should improve the quality of life now and should also last for future generations.

As suggested by Azambuja, Viale Pereira and Krimmer [6], a smart sustainable city is a territory that is able to balance the three sustainability pillars (social, economic and environment), making use of urban infrastructure and having the governance on the top of the model. In their model [6], the urban infrastructure dimension, which includes urban ICT and physical infrastructure, is set as the ground layer of the smart sustainable city to connect all necessary infrastructure to deliver city services. This base dimension is often referred as the built environment and digital layer of a smart city. In the middle of the model, the three dimensions social, economic, and environmental represent the sustainability of the city; and on the top is the governance domain, which is responsible for the coordination of all city elements to ensure that all domains are being considered to reach sustainability. This comprehensive model shows that a smart sustainable city extends the smart city concept. SSC is an interdisciplinary concept that comprises different domains where technology serves as a means and not as a goal itself. According to a recent study [20], the improvement of quality of life of urban residents and the enhancement of city functioning can be achieved through activities covering the five dimensions suggested by Azambuja et al. [6]. Thus, this model was used in this study to guide the identification and classification of potential challenges and enablers for the development of SSCs.

\subsection{Method}

The methodological approach used to answer "What are the main enablers and challenges for the development of Smart Sustainable
Cities?" was a systematic literature review, which is recommended when the domain of study demands an association of different academic disciplines [21]. This methodology helps to summarize evidence in an accurate way [22] and is more reliable than traditional narrative reviews in the sense that the literature is selected using a transparent and reproducible process, which increases the methodological rigor and minimizes bias [23]. To accomplish the systematic literature review, it was taken into consideration the recommendations of the new version of the Preferred Reporting Items for Systematic Reviews and Meta-Analyses-PRISMA 2020 Statement [22], which provides updated reporting guidance for systematic reviews. In addition, it was considered the guidelines of Wolfswinkel, Furtmueller and Wilderom [24], which suggest a five-step method for reviewing the literature. The step-by-step method applied in this research consists of the steps described in the following paragraphs and illustrated in Figure 1.

The first step was dedicated to defining the research plan, the inclusion and exclusion criteria. Considering the aim of this review, the author defined the keywords and the set of inclusion and exclusion criteria to be used. As this study aimed to identify aspects related to the development of smart sustainable cities, the term "smart sustainable city" and its variations (e.g., sustainable smart city, smart and sustainable city, etc.) were used. This selection distinguishes the present research from other studies that searched for the word "smart city" (without the word sustainable). The inclusion criteria were determined as academic journal articles and conference papers available online in full-text and published in English, which are relevant to the study aim and to answer the research question. Examples of relevant papers are studies mentioning driving forces, enablers, challenges, barriers, technologies, and tools used (ICT), innovations, and smart governance aspects. The exclusion criteria were defined by publications that did not mention any factors impacting the SSC development or papers presenting insufficient description of the investigation methods or results validation (i.e., weak methodology).

The second step was the search itself. The search task of relevant studies for review was undertaken in May 2019 using Scopus and Web of Science. The query string used in the databases was: (("smart sustainable cit*") OR ("sustainable smart cit*") OR ("smart and sustainable cit*") OR ("sustainable and smart cit*") OR ("smart sustainability")). The search allowed for instances of the keywords in the article title, abstract and keywords list. Since SSC is a multidomain field, the journals were not limited to one specific area. Furthermore, neither starting publication date nor end date was introduced in the search. The query resulted in 221 records in Scopus and 193 records in Web of Science, totalizing 414 records. Figure 1 summarizes the literature identification, screening, and inclusion process through the PRISMA flowchart.

The third step was the selection of the literature sample. When doing a systematic literature review, the first step of the selection phase is to look for double items; therefore, the author manually checked the total list of 414 records obtained in the search phase to eliminate duplicates, resulting in 271 unique records. After the identification phase, the screening phase aimed to verify the records according to the inclusion and exclusion criteria prior defined. The document type and the availability online and in English were 


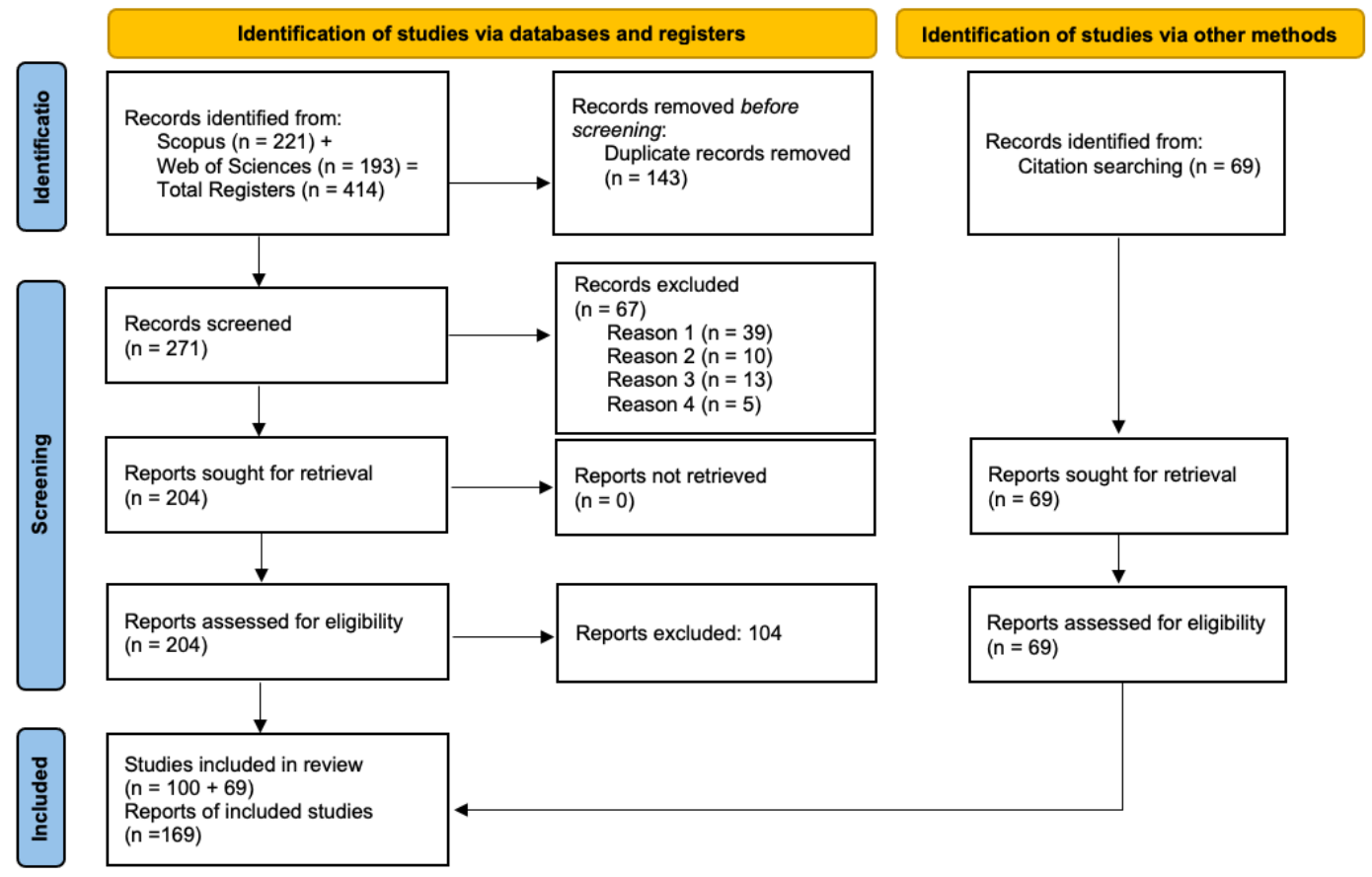

Figure 1: Literature search and selection from the Preferred Reporting Items for Systematic Reviews and Meta Analyses (PRISMA) flowchart.

verified. After removing books, book chapters or book reviews (exclusion reason 1, 39 records), conference reviews/proceeding lists (exclusion reason 2, 10 records), editorials, notes or news (exclusion reason 3, 13 records), and records not available online and in English (exclusion reason 4, 5 records), 204 papers were assessed for eligibility. The full texts of these initially screened articles were then read against the research aim. This resulted in 100 eligible articles. Following the forward and backward method [24, 25], 69 publications were added for a better understanding of the SSC development process. With the inclusion of the additional literature through citation searching, the total number of studies included in the review reached 169 records.

After searching and selecting the sample of articles, they were analysed and classified in papers containing enablers, drivers and/or barriers, challenges, etc. In addition, the drivers and barriers were coded according to SSC dimensions (governance, social, environmental, economic, and urban infrastructure), with the support of the NVIVO Software. If one paper mentioned an aspect of more than one dimension, it was included in more than one category. The SSC conceptual framework presenting the SSC domains and its characteristics (see 2.1) was used as a point of departure to organise the results; however, the scheme was updated and enlarged during the research analysis. Codes were inductively derived throughout the analysis stage, characterizing an iterative process to identify key aspects to consider [24, 26]. Various reviewing cycles were applied, classifying the drivers and barriers into sub-categories.

The last step performed in this review was the structure of the content, or in other words, the writing up and the presentation of the findings in the format of a literature review paper. The findings were summarized in two tables, one for drivers and one for barriers. Each table presents the list of factors (driver or barrier) coded during the analysis of the paper (classified according to the SSC domain) and their references.

\section{DRIVERS AND BARRIERS FOR SMART SUSTAINABLE CITY DEVELOPMENT}

This section brings aspects that could facilitate or hinder the development of SSCs. Table 1 lists the 57 drivers and 63 barriers, grouped into the SSC dimensions SSC dimensions: social, economic, environment, governance, and urban infrastructure ${ }^{1}$.

The drivers and barriers classified under the social dimension embrace aspects related to people and communities. Authors indicated the importance of the provision of urban services [13, 27-29] such as education facilities to elevate the literacy rate and to generate workforce [30-36]. Community development, promotion of collectivism and volunteering were also mentioned [27, 28, 37]. In terms of barriers, citizens are not aware of what is happening nor of the importance of their participation, consequently, the lack of citizens' participation is a barrier for SSC development. Further, citizens do not trust on government $[38,39]$, fact that hinder their support to smart initiatives.

The economic factors refer to aspects of financial, innovation, employment, management of resources and related aspects. Innovation ecosystems, and the creation of living and urban labs were highly mentioned by academics. Another enabler is the use of

\footnotetext{
${ }^{1}$ The list of drivers and barriers containing more details and their references is available in Appendice A.
} 
Table 1: Drivers and Barriers for Smart Sustainable City development.

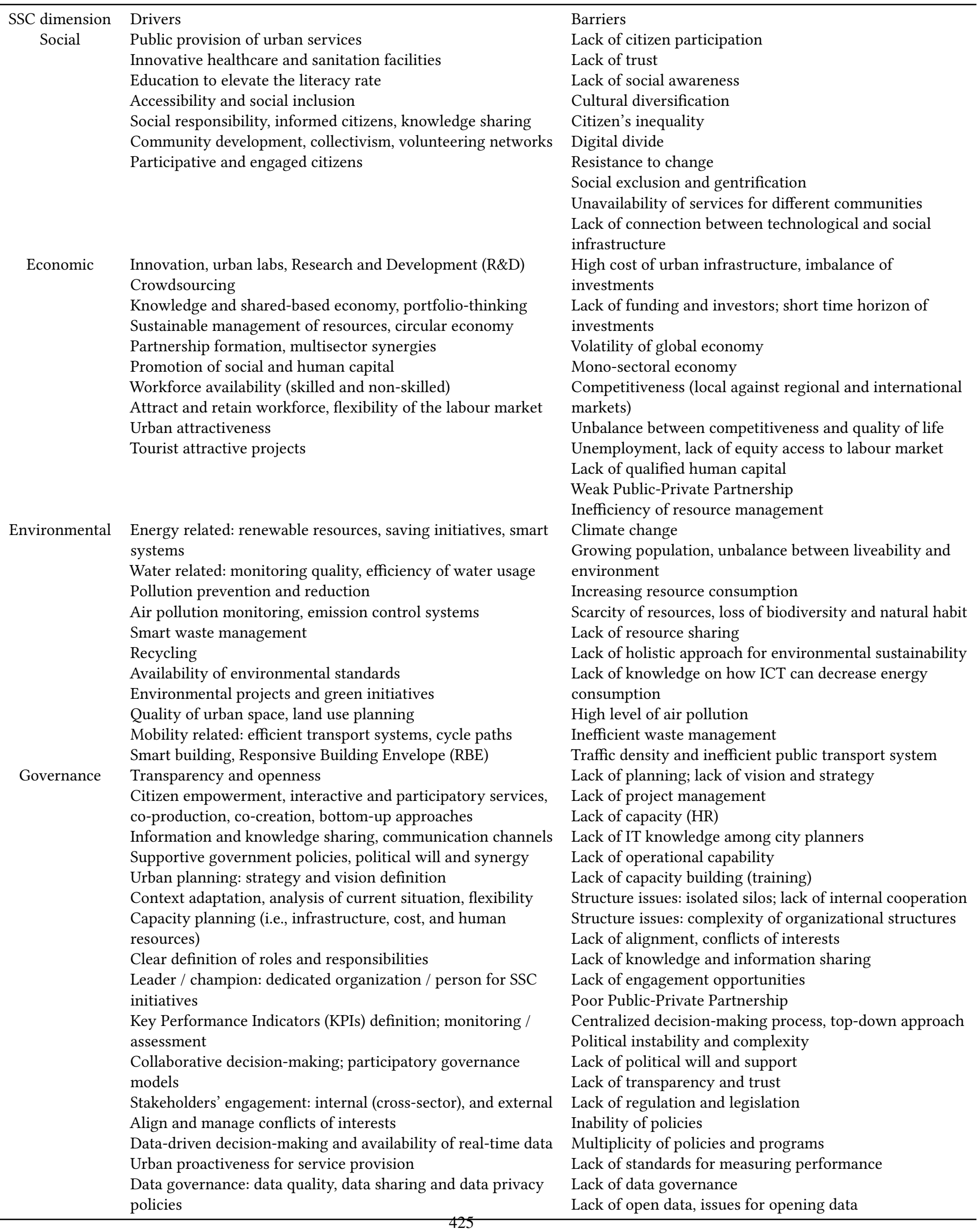


Table 1: Continued

\begin{tabular}{cll}
\hline Urban & Physical infrastructure integration & Urban infrastructure deterioration \\
Infrastructure & Affordable housing facilities, such as water and energy supply & Deficit of technological infrastructure \\
& Adoption of innovative construction techniques & Lack of infrastructure integration, complexity of \\
& Connectivity, broadband, access to internet facilities & networks \\
Interoperability and integrated ICT & Technological obsolescence, systems failures, \\
& Security verification tools / systems & infrastructure fragility \\
Advance ICT, intelligent technologies in urban services & Lack of systems interoperability and lack of \\
Smart grid; intelligent energy management systems & integration standards \\
Use of Geographical Information Systems (GIS) & Lack of systems security, privacy violation \\
Data processing: modelling imperfect data; data exchange & Poor quality of ICT-based services \\
Data analytic capacity; Business Intelligence (BI) & Lack of data integration, complexity of opening and \\
Internet of Things (IoT) & linking data \\
Big Data & Lack of data management, huge volume of data \\
& Lack of cloud and Fog computing \\
& Vendor locking \\
\hline
\end{tabular}

crowdsourcing as an alternative way to foster urban innovation as it helps to generate new ideas serving as an engagement platform. Other perspective of economic enabler is related to an effective management of urban resources, mentioned by Zhang et al. [40] as 'cleaner production', which aims to avoid waste and to maximize economic benefits. Moving to the economic barriers, the high cost of urban infrastructure was strongly stressed by academics. In addition, authors criticized the imbalance on investments regarding hard infrastructure (physical, hardware, sensors, systems) and soft infrastructure (capabilities) [2].

Environmental aspects are related to the use of renewable energy sources, smart waste management, land use planning, pollution control and prevention. The literature presents cases of initiatives highlighting the 'ecologic' side of SSCs with the potential of using modern technologies for lower resource consumption and carbon emission [41], and the benefits of using renewable energy sources [42]. In terms of barriers, ensuring environmental sustainability and building eco-friendly environment are challenging aims.

Moving to the governance dimension, SSC governance should be transparent [28, 43, 44], make use of open government approaches [28, 45-47] and should empower and engage citizens since the design of (interactive) services [45, 48]. Knowledge and information sharing were also mentioned as good practice $[19,49]$ to foster open and collaborative environments [45]. Likewise, many papers mentioned the involvement of multiple stakeholders and the creation of partnerships and cooperation. Among the list of governance barriers are the lack of planning, lack of communication, lack of leadership to run smart developments effectively. As a consequence, the uncoordinated implementation of initiatives might result in isolated efforts creating the risk of putting projects on hold due to the lack of resources [28]. Another range of challenges refer to the complexity of organizational structures and political issues. Frequently, the administrative structure of cities is organized in isolated silos (operational nodes) occasioning a lack of internal coordination and cooperation within city's agencies.

In terms of urban infrastructure drivers, scholars stated that specialized technologies like big data through IoT, and big data processing through AI bring emerging promises for city's design and management [50]. Allam and Dhunny [51] mentioned applications of AI that could benefit the development of SSC, such as AI for education, environment, health care, policy, mobility and sustainability. However, in order to benefit from the use of those emerging technologies, cities should have a robust infrastructure of systems and devices that are able to capture, process and spread data within different sources [18, 45, 52], and physical infrastructure integration, optical networks to support the communication of different data centres.

\section{DISCUSSION}

As seen, the drivers and barriers identified in this study are not exclusive from one or another dimension, confirming the interplay among the SSC dimensions. The literature highlights the "overlap" of dimensions. For example, the barrier "lack of skilled people" can be either classified under the social dimension [15] or under the economic one [44]. Similarly, the barrier "lack of investments in IT training" was categorised [18] as an economic challenge due to the high cost of IT; nevertheless, the lack of capacity (capabilities, skills) is classified in this review as governance issue. Connecting urban infrastructure and governance, authors are concerned with the existing lack of technologically comprehensive human resources. For instance, Yarime [53] highlights the need of creating capacity for data management. The lack of IT knowledge is considered as a capacity issue, thus, is a governance-related aspect. Besides the need of operational IT workforce, scholars mentioned the lack of IT knowledge among public authorities and policy makers [54] in order to help the digital transformation.

The results of this study emphasise the importance of governance for SSC development. Almost all the papers analysed (94\%) mentioned at least one governance driver or barrier $(63 \%$ mentioned drivers and $60 \%$ barriers). Some challenges correspond exactly to the lack of an enabler. For instance, some scholars indicated "information and knowledge sharing" as driver for SSC success, whereas other authors underlined that the lack of information sharing results in conflicts of interests and lack of engagement [55]. Another important governance aspect is political instability. One way to 
mitigate consequences of this challenge is the definition of a city vision and the creation of a strategic planning for that is not directly associated to any political party [56] in order to have a sustainable (long-term) initiative. Another governance aspect is the use of policies, which must contemplate multidomain aspects related to mobility, health, security, and education [13]; stimulating social inclusion and innovation to drive economic growth [57].

Most studies have a technological focus, due to the "smart" aspect of SSCs. Among the 169 analysed papers, 140 (83\%) mentioned at least one urban infrastructure driver or barrier. The results show that the SSC academic literature centres more on ICT than on urban physical infrastructure; however, infrastructure aspects are related. Furthermore, some aspects identified as drivers may cause side effects. For instance, big data can support the design, monitoring and service provision [19]; nevertheless, the city infrastructure should be in line with the use of these technologies, being a challenge.

\section{CONCLUSIONS}

Through an extensive systematic literature review comprising 169 articles, this study addressed the question of "What are the main enablers and challenges for the development of Smart Sustainable Cities?". In this investigation, it was possible to identify 57 drivers and 63 barriers that influence the progress of SSC, which were classified according to the main SSC domains (social, environmental, economic, governance, and urban infrastructure). The findings show the nuances of SSC are not generally applicable to smart cities. The addition of the word "sustainable" to the term smart city creates the idea of something that meets the needs of the present without compromising the ability of future generations. Furthermore, this study confirms that SSC is not a research field itself, but a concept that connects different disciplines.

Reflecting the number of identified factors and the number of references mentioning each SSC domain, 'governance' can be considered as the most significant domain for smart sustainable city development followed by 'urban infrastructure, 'environment, 'social', and 'economic'. The findings indicated a relation between many identified drivers and barriers, suggesting that many SSC challenges could be avoided or overcame with good governance practices. Moreover, the SSC development is a complex phenomenon that needs to be addressed in a holistic way by contemplating all SSC domains to generate sustainable impacts.

In terms of contribution, this review contributes to the gap of holistic studies investigating factors impacting the development of SSC offering a comprehensive list of drivers and barriers. Therefore, it has the potential to help different stakeholders, such as decision makers, public administrators, and practitioners in the identification of aspects to consider when developing SSC initiatives that can create long-term benefits.

This study has embedded some limitations. First, the data collection for the systematic literature review was performed in Spring 2019. Nevertheless, the author performed the same search in Spring 2021 to verify if the papers published between May 2019 and May 2021 were mentioning novel drivers and/or barriers that were not included in the initial results. A sample of $20 \%$ of those new papers were checked and no expressively new driver nor barrier was found, meaning that the study reached data saturation [58]. Thus, this data collection limitation does not affect the results of this research, confirming its relevance. Second, the literature search covered only peer-reviewed journals and full conference papers indexed at Web of Sciences and Scopus. Third, the author used a conceptual framework to guide the identification and classification of potential factors that affects the development of SSC, which covers five domains; however, there might be other models that could indicate a different set of factors that were not covered by the selected SSC framework. In addition, the identified aspects were not analysed in detail, and future work could perform a deeper analysis and prioritization of them. The recognized drivers and barriers could be evaluated further to find out their causal relations in smart sustainable city development. Lastly, one aspect labelled as an enabler could also be a barrier when there is a "lack of" such aspect, and this situation may vary considering different contexts.

\section{ACKNOWLEDGMENTS}

This work has been supported by the European Commission through the H2020 project Finest Twins (grant No. 856602).

\section{REFERENCES}

[1] Bibri, S.E. and Krogstie, J. 2017. Smart sustainable cities of the future: An extensive interdisciplinary literature review. Sustainable Cities and Society. 31, (2017), 183212. DOI:https://doi.org/10.1016/j.scs.2017.02.016.

[2] Ahvenniemi, H. et al. 2017. What are the differences between sustainable and smart cities? Cities. 60, (2017), 234-245. DOI:https://doi.org/10.1016/j.cities.2016. 09.009 .

[3] Angelidou, M. et al. 2018. Enhancing sustainable urban development through smart city applications. Fournal of Science and Technology Policy Management. 9, 2 (2018), 146-169. DOI:https://doi.org/10.1108/JSTPM-05-2017-0016.

[4] Huovila, A. et al. 2019. Comparative analysis of standardized indicators for Smart sustainable cities: What indicators and standards to use and when? Cities. 89, June 2018 (2019), 141-153. DOI:https://doi.org/10.1016/j.cities.2019.01.029.

[5] Kramers, A. et al. 2014. Planning for smart sustainable cities: Decisions in the planning process and actor networks. ICT for Sustainability 2014 (ICT4S-14) (2014).

[6] Azambuja, L.S. de et al. 2020. Clearing the Existing Fog over the Smart Sustainable City Concept: Highlighting the Importance of Governance. Proceedings of the 13th International Conference on Theory and Practice of Electronic Governance. ICEGOV2020. ACM. (Athens, Greece, 2020). DOI: https://doi.org/10.1145/3428502. 3428595

[7] Höjer, M. and Wangel, J. 2014. Smart sustainable cities: Definition and challenges. Advances in Intelligent Systems and Computing. 310, (2014), 333-349. DOI:https: //doi.org/10.1007/978-3-319-09228-7 20.

[8] Bibri, S.E. and Krogstie, J. 2018. The Big Data Deluge for Transforming the Knowledge of Smart Sustainable Cities. Proceedings of the 3rd International Conference on Smart City Applications - SCA '18 (New York, New York, USA, Oct. 2018), 1-10.

[9] Guedes, A.L.A. et al. 2018. Smart cities: The main drivers for increasing the intelligence of cities. Sustainability (Switzerland). 10, 9 (2018), 1-19. DOI:https: //doi.org/10.3390/su10093121.

[10] Geldenhuys, H.J. et al. 2018. Literature review for infrastructure transition management towards smart sustainable cities. 4th IEEE International Symposium on Systems Engineering, ISSE 2018 - Proceedings. (2018), 1-7. DOI:https: //doi.org/10.1109/SysEng.2018.8544416.

[11] Bibri, S.E. and Krogstie, J. 2017. The core enabling technologies of big data analytics and context-aware computing for smart sustainable cities: a review and synthesis. Fournal of Big Data. 4, 1 (2017), 50. DOI:https://doi.org/10.1186/s40537017-0091-6.

[12] Bibri, S.E. 2018. A foundational framework for smart sustainable city development: Theoretical, disciplinary, and discursive dimensions and their synergies. Sustainable Cities and Society. 38, December 2017 (2018), 758-794. DOI:https: //doi.org/10.1016/j.scs.2017.12.032.

[13] Yigitcanlar, T. et al. 2019. Can cities become smart without being sustainable? A systematic review of the literature. Sustainable Cities and Society. 45, November 2018 (2019), 348-365. DOI:https://doi.org/10.1016/j.scs.2018.11.033.

[14] Yadav, G. et al. 2019. Developing a sustainable smart city framework for developing economies: An Indian context. Sustainable Cities and Society. 47, January (2019), 101462. DOI:https://doi.org/10.1016/j.scs.2019.101462.

[15] Ibrahim, M. et al. 2015. Challenges facing e-government and smart sustainable city: An arab region perspective. Proceedings of the European Conference on eGovernment, ECEG (2015), 396-402. 
[16] Khan, H.H. et al. 2020. Challenges for sustainable smart city development: A conceptual framework. Sustainable Development. 28, 5 (Sep. 2020), 1507-1518. DOI:https://doi.org/10.1002/sd.2090.

[17] Goyal, S. et al. 2018. Identification and prioritization of barriers in building smart cities. International fournal of Mechanical Engineering and Technology. 9, 4 (2018), 819-827.

[18] Rana, N.P. et al. 2019. Barriers to the Development of Smart Cities in Indian Context. Information Systems Frontiers. 21, 3 (Jun. 2019), 503-525. DOI:https: //doi.org/10.1007/s10796-018-9873-4.

[19] D'Auria, A. et al. 2018. Modern conceptions of cities as smart and sustainable and their commonalities. Sustainability (Switzerland). 10, 8 (2018). DOI:https: //doi.org/10.3390/su10082642.

[20] Baraniewicz-Kotasińska, S. 2020. Smart city. Four approaches to the concept of understanding. Urban Research \& Practice. (Sep. 2020), 1-24. DOI:https://doi.org/ 10.1080/17535069.2020.1818817.

[21] Mora, L. et al. 2017. The First Two Decades of Smart-City Research: A Bibliometric Analysis. Journal of Urban Technology. 24, 1 (2017), 3-27. DOI:https://doi.org/10. 1080/10630732.2017.1285123.

[22] Page, M.J. et al. 2021. The PRISMA 2020 statement: An updated guideline for reporting systematic reviews. PLoS medicine. 18, 3 (2021), e1003583. DOI:https: //doi.org/10.1371/journal.pmed.1003583.

[23] Tranfield, D et al. 2003. Towards a Methodology for Developing EvidenceInformed Management Knowledge by Means of Systematic Review. British fournal of Management. 14, 3 (2003), 207-222. DOI:https://doi.org/10.1111/14678551.00375 .

[24] Wolfswinkel, J.F. et al. 2013. Using grounded theory as a method for rigorously reviewing literature. European fournal of Information Systems. 22, 1 (2013), 45-55. DOI:https://doi.org/10.1057/ejis.2011.51.

[25] Webster, J. and Watson, R.T. 2002. Analyzing the Past to Prepare for the Future: Writing a Literature Review. MIS Quarterly. 26, 2 (2002).

[26] Ruhlandt, R.W.S. 2018. The governance of smart cities: A systematic literature review. Cities. 81, June (2018), 1-23. DOI:https://doi.org/10.1016/j.cities.2018.02 014

[27] Macke, J. et al. 2018. Smart city and quality of life: Citizens' perception in a Brazilian case study. Journal of Cleaner Production. 182, (2018), 717-726. DOI:https //doi.org/10.1016/j.jclepro.2018.02.078.

[28] Aina, Y.A. 2017. Achieving smart sustainable cities with GeoICT support: The Saudi evolving smart cities. Cities. 71, August 2016 (2017), 49-58. DOI:https: //doi.org/10.1016/j.cities.2017.07.007.

[29] [29]Glasmeier, A.K. and Nebiolo, M. 2016. Thinking about smart cities: The travel of a policy idea that promises a great deal, but so far has delivered modest results. Sustainability (Switzerland).

[30] Adapa, S. 2018. Indian smart cities and cleaner production initiatives - Integrated framework and recommendations. Fournal of Cleaner Production. 172, (Jan. 2018), 3351-3366. DOI:https://doi.org/10.1016/j.jclepro.2017.11.250.

[31] Barns, S. 2018. Smart cities and urban data platforms: Designing interfaces for smart governance. City, Culture and Society. 12, December 2016 (2018), 5-12. DOI:https://doi.org/10.1016/j.ccs.2017.09.006.

[32] ]Fernandez-Anez, V. et al. 2018. Smart City implementation and discourses: An integrated conceptual model. The case of Vienna. Cities. 78, November 2017 (2018), 4-16. DOI:https://doi.org/10.1016/j.cities.2017.12.004.

[33] Grossi, G. and Pianezzi, D. 2017. Smart cities: Utopia or neoliberal ideology? Cities. 69, April (2017), 79-85. DOI:https://doi.org/10.1016/j.cities.2017.07.012.

[34] Kummitha, R.K.R. and Crutzen, N. 2017. How do we understand smart cities? An evolutionary perspective. Cities. 67, July 2016 (2017), 43-52. DOI:https://doi.org/ 10.1016/j.cities.2017.04.010.

[35] Lopes, I.M. and Oliveira, P. 2017. Can a small city be considered a smart city? Procedia Computer Science. 121, (2017), 617-624. DOI:https://doi.org/10.1016/j. procs.2017.11.081.

[36] Praharaj, S. et al. 2018. Urban innovation through policy integration: Critical perspectives from 100 smart cities mission in India. City, Culture and Society. 12 , January 2017 (2018), 35-43. DOI:https://doi.org/10.1016/j.ccs.2017.06.004.

[37] Vakali, A. et al. 2017. Vol4All: A Volunteering Platform to Drive Innovation and Citizens Empowerment. Proceedings of the 26th International Conference on World Wide Web Companion. 4, (2017), 1173-1178. DOI:https://doi.org/10.1145/3041021. 3054712.

[38] Balta-Ozkan, N. et al. 2013. Social barriers to the adoption of smart homes. Energy Policy. 63, (Dec. 2013), 363-374. DOI:https://doi.org/10.1016/j.enpol.2013.08.043.

[39] Monzon, A. 2015. Smart Cities Concept and Challenges. 2015 International Conference on Smart Cities and Green ICT Systems (SMARTGREENS). (2015), 17-31.
DOI.https://doi.org/10.1007/978-3-642-33489-4 4.

[40] Zhang, X. et al. 2019. An efficient data delivery and scheduling scheme for smart and sustainable cities. Fournal of Cleaner Production. 215, (2019), 497-513. DOI:https://doi.org/10.1016/j.jclepro.2019.01.038.

[41] Martin, C. et al. 2019. Smart-sustainability: A new urban fix? Sustainable Cities and Society. 45, February 2018 (2019), 640-648. DOI:https://doi.org/10.1016/j.scs. 2018.11.028.

[42] Lazaroiu, G.C. and Roscia, M. 2012. Definition methodology for the smart cities model. Energy. 47, 1 (2012), 326-332. DOI:https://doi.org/10.1016/j.energy.2012. 09.028 .

[43] Ramaswami, A. et al. 2016. Meta-principles for developing smart, sustainable, and healthy cities. Science. 352, 6288 (2016), 940-943. DOI:https://doi.org/10.1126/ science.aaf7160.

[44] Chourabi, H. et al. 2012. Understanding smart cities: An integrative framework. Proceedings of the Annual Hawaii International Conference on System Sciences (2012), 2289-2297.

[45] Lee, J.H. et al. 2014. Towards an effective framework for building smart cities: Lessons from Seoul and San Francisco. Technological Forecasting and Social Change. 89, (2014), 80-99. DOI:https://doi.org/10.1016/j.techfore.2013.08.033.

[46] Meijer, A. and Rodríguez Bolívar, M.P. 2013. Governing the Smart City: ScalingUp the Search for Socio-Techno Synergy. EGPA Annual Conference. 2013, (2013), $1-13$.

[47] Khan, Z. et al. 2017. Towards a secure service provisioning framework in a Smart city environment. Future Generation Computer Systems. 77, (Dec. 2017), 112-135. DOI:https://doi.org/10.1016/J.FUTURE.2017.06.031.

[48] Alawadhi, S. et al. 2012. Building Understanding of Smart City Initiatives. Electronic Government. EGOV 2012. Lecture Notes in Computer Science. H.J. Scholl et al., eds. Springer, Berlin, Heidelberg. 40-53.

[49] Keshvardoost, S. et al. 2019. Developments of policies related to smart cities: A critical review. Proceedings - 11th IEEE/ACM International Conference on Utility and Cloud Computing Companion, UCC Companion 2018. (2019), 365-369. DOI:https: //doi.org/10.1109/UCC-Companion.2018.00083.

[50] Costin, A. and Eastman, C. 2019. Need for Interoperability to Enable Seamless Information Exchanges in Smart and Sustainable Urban Systems. Fournal of Computing in Civil Engineering. 33, 3 (2019). DOI:https://doi.org/10.1061/(ASCE) CP.1943-5487.0000824.

[51] Allam, Z. and Dhunny, Z.A. 2019. On big data, artificial intelligence and smart cities. Cities. 89, January (2019), 80-91. DOI:https://doi.org/10.1016/j.cities.2019. 01.032 .

[52] Corbett, J. and Mellouli, S. 2017. Winning the SDG battle in cities: how an integrated information ecosystem can contribute to the achievement of the 2030 sustainable development goals. Information Systems fournal. 27, 4 (2017), 427-461. DOI:https://doi.org/10.1111/isj.12138.

[53] Yarime, M. 2017. Facilitating data-intensive approaches to innovation for sustainability: opportunities and challenges in building smart cities. Sustainability Science. 12, 6 (2017), 881-885. DOI:https://doi.org/10.1007/s11625-017-0498-1.

[54] Scuotto, V. et al. 2016. Internet of things: Applications and challenges in smart cities: A case study of IBM smart city projects. Business Process Management fournal. 22, 2 (Apr. 2016), 357-367. DOI:https://doi.org/10.1108/BPMJ-05-20150074.

[55] Joshi, S. et al. 2016. Developing Smart Cities: An Integrated Framework. Procedia Computer Science (2016), 902-909.

[56] Ben Letaifa, S. 2015. How to strategize smart cities: Revealing the SMART model. fournal of Business Research. 68, 7 (2015), 1414-1419. DOI:https://doi.org/10.1016/ j.jbusres.2015.01.024

[57] Caragliu, A. and Del Bo, C.F. 2019. Smart innovative cities: The impact of Smart City policies on urban innovation. Technological Forecasting and Social Change. 142, July 2018 (2019), 373-383. DOI:https://doi.org/10.1016/j.techfore.2018.07.022.

[58] Saunders, B. et al. 2018. Saturation in qualitative research: exploring its conceptualization and operationalization. Quality and Quantity. 52, 4 (2018), 1893-1907. DOI:https://doi.org/10.1007/s11135-017-0574-8.

\section{A APPENDICES}

The full list of identified drivers and barriers and their respective references can be found in the following link:

https://drive.google.com/file/d/1zKT-GpXMTkEyqULD2s-

DFw6W3sYMbCm6/view?usp=sharing 